\title{
GIANT INGUINAL HERNIA; COMPLICATIONS AND THEIR MANAGEMENT IN PATIENTS anwermuhammad610@yahoo.com
}

1. MBBS, M.S General Surgery Registrar Surgical Ward-I2, Unit-II Liaquat University of Medical \& Health Sciences Jamshoro anwermuhammad610@yahoo.com

2. MBBS, M.S General Surgery Registrar Surgical Ward-II Liaquat University of Medical \& Health Sciences Jamshoro.

3. MBBS, M.S General Surgery Registrar Surgical Emergency Unit-

Liaquat University Hospital Hirabad Hyderabad.

Correspondence Address: Dr. Muhammad Anwer Memon MBBS, M.S General Surgery Registrar Surgical Ward-12, Unit-II Liaquat University of Medical \& Health Sciences Jamshoro anwermuhammad610@yahoo.com

Article received on:

24/08/2016

Accepted for publication: 20/10/2016

Received after proof reading: 00/00/2016

\section{Dr. Muhammad Anwer Memon', Dr. Mohammad Rafique Pathan², Dr. Karim Bux ${ }^{3}$}

\begin{abstract}
Objectives: To determine the complications and their management in patients with giant inguinal hernia. Place and Duration of Study: This study was carried out in in Surgical Unit-IV, Liaquat University Hospital Jamshoro, from October 2013 to December 2015. Methodology: This study consisted of 30 patients of giant inguinoscrotal hernias. Detailed History was taken from all the patients with special regard to the inguinoscrotal swelling. Detailed Clinical examination of the patient was done .Site of swelling was especially examined for assessment of three grades. Grade-I means hernia reaching upto middle of thigh, Grade-II means inguinoscrotal contents reaching upto knee joint and Grade-III means contents going below knee level. All data was entered in a specified proforma designed for this purpose. Inclusion criteria were all diagnosed patients of giant inguinoscrotal hernia on the basis of history, clinical examination were included in this study. Exclusion criteria included patients unfit for surgery, patients below age of 12 years, patients with severe co-morbidity and morbid obese patients. Results: 30 patients included in this study. There was wide variation of age ranging from a minimum of 30 years to 70 years, mean age was $46.28+7.20$ years. The patients presented with more common in right side $21(70 \%)$ cases and left side $9(30 \%)$ cases. Patients presented with grade-I $11(36.66 \%)$ cases, grade-II $9(30 \%)$ cases, grade-III $7(23.33 \%)$ cases and grade IV $3(10 \%)$ cases. Giant inguinal hernia were operated Orchidectomy and hernioplasty $12(40 \%)$ cases, followed by Debulkation of contents and hernioplasty $9(30 \%)$ cases and Gradual Pneumoperitoneum and hernioplasty $4(13.33 \%)$ cases. Complications seen in this study was Respiratory in $3(10 \%)$ patients, Abdominal compartmental syndrome in $1(3.33 \%)$ patients, Paralytic lleus in $2(6.66 \%)$ patients and Wound Infections in $4(13.33 \%)$. Conclusion: In conclusion our study revealed it is commonly to live in our population due to ignorance of hernia poverty in remote areas and lack of knowledge of disease complications.
\end{abstract}

Key words: Giant inguino-scrotal hernia, Complications, Management.

Article Citation: Memon MA, Pathan MR, Bux K. Giant inguinal hernia; complications and their management in patients. Professional Med J 2016;23(12):1495-1498.

DOI: $10.17957 / \mathrm{TPMJ} / 16.3600$

\section{INTRODUCTION}

A giant inguino-scrotal hernia is defined as a hernia that extends below inward straight to down the middle of the thigh in the standing position. ${ }^{1}$ They contain many viscera or a very long segment of bowel loops..$^{2,3}$ Hernia is a common medical problem and inguinal hernia repair is one of the most common operations performed in the world. ${ }^{4}$ Giant inguinoscrotal herniae are uncommon in developed countries nowadays ${ }^{5}$, nonetheless they may still typically present after years of neglect. ${ }^{6}$ Patients present with progressively enlarged inguinoscrotal hernia and usually encounter difficulty in walking, sitting or lying down and their mobility is drastically restricted. Varied clinical presentation seen in such patients include acute retention of urine, gangrene and ulceration of scrotal skin and bowel obstruction. ${ }^{7,8}$

The treatment of such type of hernia is a challenge for both the patients and the surgeon because of rarity of reported cases and there is no slandered surgical procedure in place for their management Few surgical techniques have been described in the literature for repairing giant inguinoscrotal hernia. Inflations and the air inside the abdominal cavity to create space to accommodate the herniated viscera and easy repair minimal fascia tension has often employed. . $^{8,9}$ 
Contract hernia contents into the peritoneal cavity in the abdomen and chest of the forced reduction in intrathoracic pressure change, the potential for severe respiratory or heart failure, and high morbidity and mortality rates. ${ }^{10}$

\section{MATERIAL \& METHODS}

This study is an observational study of repair giant inguinoscrotal hernias was carried out in Surgical Unit-IV, Liaquat University Hospital Jamshoro, from October 2013 to December 2015.

30 patients of giant inguinoscrotal hernias admitted through the outpatient department, as well as from casualty department. Detailed History and clinical examination were taken from all the patients with special regard to the inguinoscrotal swelling. Site of swelling was especially examined for assessment of three grades. Grade -I means hernia reaching upto middle of thigh, Grade-II means inguinoscrotal contents reaching upto knee joint and Grade-III means contents going below knee level. Inclusion criteria were all diagnosed patients of giant inguinoscrotal hernia on the basis of history, clinical examination were included in study.

Exclusion criteria included patients unfit for surgery, patients below age of 12 years, patients with severe co-morbidity and morbid obese patients. Follow up of all these patients was done. $1^{\text {st }}$ visit should be early to decide resumption to work and $2^{\text {nd }}$ visit after 6 month to assess any complication and inquiry about resumption to work.

\section{RESULTS}

The 30 cases of giant inguinoscrotal hernia were operated. There was wide variation of age ranging from a minimum of 30 years to 70 years. The mean age was $46.28+7.20$ years. The patients presented with more common in right side $21(70 \%)$ cases and left side $9(30 \%)$ cases. The patients presented with grade-l 11(36.67\%) cases, grade-II $9(30 \%)$ cases, grade-III $7(23.33 \%)$ cases and grade IV $3(10 \%)$ cases. (Table-I).

The giant inguinal hernia were commonly operated Orchidectomy and hernioplasty $12(40 \%)$ cases, followed by Debulkation of contents and hernioplasty $9(30 \%)$ cases and Gradual Pneumoperitoneum and hernioplasty 4(13.33\%) cases. (Figure-1). The complications seen in this study was Respiratory in $3(10 \%)$ patients, abdominal compartmental syndrome in 1(3.33\%) patients, Paralytic lleus in $2(6.67 \%)$ patients and Wound Infections in 4(13.33\%). (Figure-2).

\begin{tabular}{|l|c|c|}
\hline \multicolumn{1}{|c|}{ Variable } & No. Patients & Percentage \\
\hline Age & \multicolumn{1}{|c|}{} \\
\hline $30-45$ years & 15 & $50 \%$ \\
\hline $46-60$ years & 9 & $30 \%$ \\
\hline $61-70$ years & 6 & $20 \%$ \\
\hline Site of Hernia & & \\
\hline Right Side & 21 & $70 \%$ \\
\hline Left Side & 09 & $30 \%$ \\
\hline Grades of Giant Inguinal Hernia & \\
\hline Grade I & 11 & $36.67 \%$ \\
\hline Grade II & 9 & $30 \%$ \\
\hline Grade III & 7 & $23.33 \%$ \\
\hline Grade IV & 3 & $10 \%$ \\
\hline \multicolumn{1}{|c|}{ Table-l. Demographic variable $\mathrm{n}=30$} \\
\hline
\end{tabular}

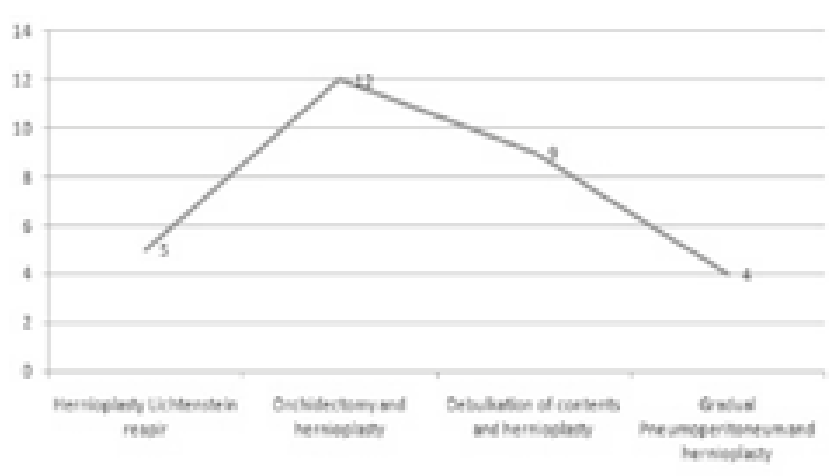

Figure-1. Management Plan

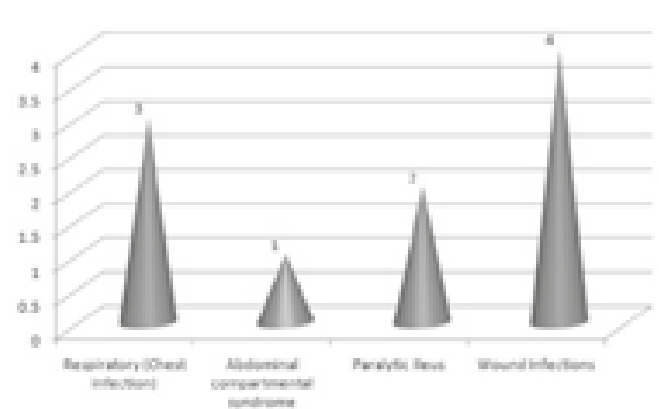

Figure-2. Post-operative Complications 


\section{DISCUSSION}

The giant inguinal hernia has now become uncommon. Hernioplasty under local anesthesia techniques performed better and better sanitary conditions, usually in the early diagnosis and surgical treatment of hernia patients should be encouraged to undergo surgical treatment of the hernia soon after diagnosis. The indirect inguinal hernia progresses through various grades of severity. ${ }^{11}$

Inguinoscrotal huge hernia repair surgery is often complex. Surgery and physiological changes associated with loss of domain growth in the period after the surgery are at risk for complications. ${ }^{12,13}$ In this report, we describe our This Hernias huge emphasis on specific management problems that occur in the treatment of hernia surgery inguinoscrotal.

In our study was wide variation of age ranging from a minimum of 30 years to 70 years, most common in $4^{\text {th }}$ and $5^{\text {th }}$ Decade of life. The mean age was $46.28+7.20$ years. However in the study of Abdul Ghafoor Dalwani ${ }^{14}$ reported fifth decade $20(66.7 \%)$ cases, sixth decade $07(23.3 \%)$ cases and seventh decade $03(10 \%)$ cases. In our study reported patients presented with more common in right side $21(70 \%)$ cases and left side $9(30 \%)$ cases. While in national study reported right sided 26(86.7\%) and left sided 04(13.33\%). ${ }^{14}$

Giant inguinal hernia divided into 4 degrees by Muhammad Hussain Ghar (M.H.L) To simplify the explanation imaginary line from the center and inguinal border at the top of the knee and giant inguinal hernia classified properly. ${ }^{14}$ However in our study patients presented with grade-I $11(36.67 \%)$ cases, grade-II $9(30 \%)$ cases, gradeIII $7(23.33 \%)$ cases and grade IV $3(10 \%)$ cases.

Huge challenge and potentially fatal complication of hernia can be a inguinoscrotal. adequate preoperative preparation and postoperative monitoring and ventilation is important to finish. More vascularized pedicle fascial flap TFL support on the mesh reinforces the repair, improves blood supply and protects the mesh and should be considered a revival of large complex abdominal hernia. ${ }^{15,16}$ Inguinal hernia surgery, normalization of life with your plastic surgeon and a general surgeon had a significant impact on patient outcomes may require close cooperation between them. ${ }^{17,18}$ In present study the giant inguinal hernia were commonly operated Orchidectomy and hernioplasty $12(40 \%)$ cases, followed by Debulkation of contents and hernioplasty $9(30 \%)$ cases and Gradual Pneumoperitoneum and hernioplasty $4(13.33 \%)$ cases.

The depletion of the hernia may have rejected the danger of injury to the previous surgery's can impair lung function and respiratory patients. Following the loss of potentially fatal heart and respiratory failure to reduce the huge hernia, and pulmonary embolism can develop And due to a' domain' rights' of the sharp increase in the height of the diaphragm into the abdominal cavity, the pressure inside the abdomen. ${ }^{18}$ In our study respiratory complications reported in $3(10 \%)$ patients.

Postoperative ileus also can increase the pressure within the abdomen. Preoperative and postoperative mechanical ventilation, chest physical therapy plays an important role. Postoperative mechanical ventilation should be discontinued soon. It's camouflage, as a precaution, although too much stress in patients withaclosedventilationfor 48hours thatisasurgery. The patient developed respiratory distress after extubation, and require additional ventilation for 4 days. ${ }^{19}$ These patients had prophylactic Heparin and Heparin 5000 units. Reduce the volume of the abdominal cavity and the abdominal contents and / or pressure reduction can be achieved by significantly debulking. Chapter extensive hernia surgery perform a inguinoscrotal total resection and omentectomy was described by Serpell L. ${ }^{10}$ However in our study abdominal compartmental syndrome in $1(3.33 \%)$ patients, paralytic ileus in $2(6.67 \%)$ patients and wound Infections in $4(13.33 \%)$. However in the study of Dalwani AG reported hematoma $05(41.6 \%)$, wound infection 04(13.33\%) and chest infection 03(10\%). ${ }^{14}$ 


\section{CONCLUSION}

Giant inguinal hernia patients in rural areas and more in the frequency of aging. It is due to carelessness hernia complications and diseases in remote areas live in poverty, ignorance is common in our population. Postoperative common complications reported in our study are wound infection and respiratory infection.

Copyright@ 20 Oct, 2016.

\section{REFERNCES}

1. Turner EJH, Malhas A, Chisti I, Oke T. Management of a giant inguinoscrotal hernia with an ulcerated base in a patient with cardiac disease. Journal of Surgical Case Reports 2010; 8-9.

2. Coetzee E, Price C, Boutall A. Simple repair of a giant inguinoscrotal hernia. Int J Surg Case Rep. 2011; 2:32-35.

3. Moreno IG. Chronic eventrations and large hernias; preoperative treatment by progressive pneumoperitoneum; original procedure. Surgery. 1947; 22(6):945-953.

4. Kovachev LS, Paul AP, Chowdhary P, Chowdhary P, Filipov ET. Regarding extremely large inguinal hernias with a contribution of two cases. Hernia. 2010; 14(2):193-197.

5. Imisairi A.H., Hadi S.M. Giant inguinal hernia. ANZ J Surg. 2011; 81(6):488.

6. Patsas A, Tsiaousis P, Papaziogas B, Koutelidakis I, Goula C,Atmatzidis K. Repair of a giant inguinoscrotal hernia. $J$ hernias and abdominal wall surg 2010; 14:305-07.

7. Guisado-Vasco P, Jaen P. Giant inguinoscrotal hernia. Australian Family Physician 2009; 38(4):222-3.

8. Vasilliadis K., Knaebel H.P., Djakovic N., NyarangiDix J., Scahmidt J., Bucher M. Challenging surgical management of a giant inguinoscrotal hernia: report of a case. Surg Today. 2010; 40(7):684-687.

9. Beitler JC, Gomes SM, Coelho AC, Manso JE. Complex inguinal hernia repairs. $J$ hernias and abdominal wall surg 2009; 13(1):61-6.

10. Valliattu AJ, Kingsnorth AN. Single-stage repair of giant inguinoscrotal hernias using the abdominal wall component separation technique. $\mathrm{J}$ hernias and abdominal wall surg 2008; 12:329-30.

11. Gillellamudi SB. Hanging Giant Inguinal Hernia. NJIRM 2010;1(4):47-8.

12. Vasiliadis K, Knaebel HP, Djakovic N, NyarangiDix J, Schmidt J, Büchler M. Challenging surgical management of a giant inguinoscrotal hernia: report of a case. Surg Today 2010; 40: 684-7.

13. Patsas A, Tsiaousis P, Papaziogas B, Koutelidakis I, Goula C, Atmatzidis K. Repair of a giant inguinoscrotal hernia. Hernia 2010; 14: 305-7.

14. Dalwani AG, Shaikh AR, Memon S. Management of Giant Inguinal Hernia. JLUMHS JANUARY - APRIL 2009; 8(1):29-33.

15. Mehendale FV, Taams KO, Kingsnorth AN. Repair of a giant inguinoscrotal hernia. $\mathrm{Br} J$ Plastic-Surg 2000; 53(6):525-9.

16. El Saadi AS, AI Wadan AH, Hamerna S. Approach to a giant inguinoscrotal hernia. Hernia 2005; 9: 277-9.

17. Monestiroli UM, Bondurri A, Gandini F, Lenna G, Vellini S, Danelli P. Giant inguinoscrotal hernia. Tech Coloproctol 2007; 11: 283-4.

18. Cady B, Brooke-Cowden GL. Repair of massive abdominal wall defects: combined use of pneumoperitoneum and Marlex mesh. Surg Clin North Am 1976; 56(3): 559-70.

19. Kyle SM, Lovie MJ, Dowle CS. Massive inguinal hernia. Br J Hosp Med 1990; 43(5): 383-4.

\begin{tabular}{|c|c|c|c|}
\hline \multicolumn{2}{|c}{ AUTHORSHIP AND CONTRIBUTION DECLARATION } \\
\hline Sr. \# & Author-s Full Name & \multicolumn{1}{|c|}{ Contribution to the paper } & Author=s Signature \\
\hline 1 & Dr. M. Anwer Memon & $\begin{array}{l}\text { Conception, design, Critical } \\
\text { revision of the article for } \\
\text { important intellectual content } \\
\text { Statistical expertise, Critical } \\
\text { revision of the article for } \\
\text { important intellectual content } \\
\text { Drafting of the article }\end{array}$ \\
\hline 3 & Dr. M. Rafique Pathan & Dr. Karim Bux & \\
\hline
\end{tabular}

